\title{
Effector prediction in host-pathogen interaction based on a Markov model of a ubiquitous EPIYA motif
}

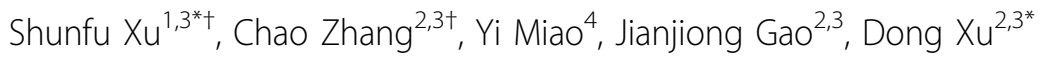

From The ISIBM International Joint Conference on Bioinformatics, Systems Biology and Intelligent Computing (IJCBS)

Shanghai, China. 3-8 August 2009

\begin{abstract}
Background: Effector secretion is a common strategy of pathogen in mediating host-pathogen interaction. Eight EPIYA-motif containing effectors have recently been discovered in six pathogens. Once these effectors enter host cells through type III/IV secretion systems (T3SS/T4SS), tyrosine in the EPIYA motif is phosphorylated, which triggers effectors binding other proteins to manipulate host-cell functions. The objectives of this study are to evaluate the distribution pattern of EPIYA motif in broad biological species, to predict potential effectors with EPIYA motif, and to suggest roles and biological functions of potential effectors in host-pathogen interactions.

Results: A hidden Markov model (HMM) of five amino acids was built for the EPIYA-motif based on the eight known effectors. Using this HMM to search the non-redundant protein database containing 9,216,047 sequences, we obtained 107,231 sequences with at least one EPIYA motif occurrence and 3115 sequences with multiple repeats of the EPIYA motif. Although the EPIYA motif exists among broad species, it is significantly overrepresented in some particular groups of species. For those proteins containing at least four copies of EPIYA motif, most of them are from intracellular bacteria, extracellular bacteria with T3SS or T4SS or intracellular protozoan parasites. By combining the EPIYA motif and the adjacent SH2 binding motifs (KK, R4, Tarp and Tir), we built HMMs of nine amino acids and predicted many potential effectors in bacteria and protista by the HMMs. Some potential effectors for pathogens (such as Lawsonia intracellularis, Plasmodium falciparum and Leishmania major) are suggested.

Conclusions: Our study indicates that the EPIYA motif may be a ubiquitous functional site for effectors that play an important pathogenicity role in mediating host-pathogen interactions. We suggest that some intracellular protozoan parasites could secrete EPIYA-motif containing effectors through secretion systems similar to the T3SS/ T4SS in bacteria. Our predicted effectors provide useful hypotheses for further studies.
\end{abstract}

\section{Background}

As a complex and interesting relation between organisms in ecology and evolution, host-pathogen interaction is a basis of infectious diseases[1]. Pathogens span a broad

\footnotetext{
* Correspondence: xushfu@njmu.edu.cn; xudong@missouri.edu

+ Contributed equally

'Department of Gastroenterology, the First Affiliated Hospital of Nanjing Medical University, Jiangsu 210029, China

${ }^{2}$ Department of Computer Science, University of Missouri, Columbia, MO 65211, USA

Full list of author information is available at the end of the article
}

spectrum of biological species, including viruses, bacteria, fungi, protozoa, and multicellular parasites. In all these cases, a pathogen causing an infection usually exhibits an extensive interaction with the host during pathogenesis. The cross-talks between a host and a pathogen allow the pathogen to successfully invade the host organism, to breach its immune defence, as well as to replicate and persist within the organism. One of the most important and therefore widely studied groups of host- pathogen interactions is the interaction between pathogen protein 
(effector) and host cells. Effectors are secreted from pathogens' secretion systems. So far five types of secretion systems have been identified (Types I-V). Among them, T3SS (Type III Secretion System) and T4SS (Type IV Secretion System) can cross bacterial cell walls and host eukaryotic cell membranes to deliver effectors into host cells directly without going through extracellular matrix[2]. Those effectors can manipulate host cell functions once entering host cell[2]. Identifying effectors and exploring their molecular mechanisms not only are critical to understanding the disease mechanisms but also provide theoretical foundations for infectious disease diagnosis, prognosis and treatment $[3,4]$.

A well-studied effector is Cytotoxin-associated gene A (CagA), a most important virulence factor in Helicobacter pylori (H. pylori), which is one of the major pathogens of upper gastrointestinal diseases (e.g., peptic ulcer and gastric cancer)[5]. CagA can be delivered into gastric epithelial cells by the T4SS of $H$. pylori. Recent studies of CagA sequences found that they have a variable region within which the EPIYA (glutamic acid-prolineisoleucine-tyrosine-alanine) motif repeats from once to seven times. Tyrosine in the EPIYA motif can be phosphorylated in the host cell. The phosphorylated CagA protein binds to a phosphatase SHP-2, which will interfere with the signal transduction pathway of the host cell and manipulate cell growth, differentiation and apoptosis[6-8]. This interference causes a restructure of the host cell cytoskeleton, cell scattering as well as invasive growth of cells, and formation of hummingbird phenotype with gastric epithelial cells. Such a process not only is considered an important strategy of interaction between $H$. pylori and host cell, but also is the most significant mechanism of pathogenesis and carcinogenesis of H.pylori[9-11].

In recent years, studies have discovered other pathogens that can also secrete effectors to manipulate the host cells through phosphorylation during the interaction process between hosts and pathogens (e.g. Anaplasma phagocytophilum[12,13] and Bartonella henselae[14-16]). These effectors cause rearrangements of host cell cytoskeleton, NF-kB activation and apoptosis inhibition[17]. Table 1 lists eight effectors from six pathogens. They contain 28 experimentally identified phosphorylation sequences, all of which have the similar pattern to the EPIYA motif in CagA[15]. This finding leads to our hypothesis that the EPIYA-like motif and its phosphorylation, together with its interference of host cells, may be a general mechanism of pathogenesis. Based on this novel hypothesis, we used the effectors in Table 1 to build an EPIYA-motif-based hidden Markov model (HMM), and then searched the current protein database to identify more proteins with the EPIYA motif. Through studying the distribution and features of EPIYA motif in different species and genuses, we attempted to better understand the function of EPIYA motif, especially the role of EPIYA motif during the interaction process between pathogens and hosts.

\section{Results \& discussion}

\section{Building and using hidden Markov model}

Using the 28 experimentally identified phosphorylated motif sequences in Table 1, we built the sequence logo as shown in Figure 1. In this logo, the fourth position of the EPIYA motif is always tyrosine $(Y)$, which can be phosphorylated. The first and third positions have small variations. The amino acids in the first position are primarily glutamic acid (E), together with asparagine $(\mathrm{N})$. Most residues in the third position are isoleucine (I) and leucine (L), two very similar amino acids. The second and fifth positions have big variations. The second position varies from proline $(\mathrm{P})$, serine $(\mathrm{S})$ to asparagine $(\mathrm{N})$. The fifth position mainly contains alanine (A), glutamic acid (E) and aspartic acid (D). These 28 sequences were used to build and calibrate the HMM by applying Hmmer 2.3.2 (http://hmmer.janelia.org). We then employed the HMM to search the protein non-redundant (NR) database, which contains $9,216,047$ protein sequences. The search yielded 107,231 sequences containing at least one copy of EPIYA motif and 3115 sequences with multiple repeats of the EPIYA motif, where the highest number of repeats in a single protein is 29 (see Table 2).

We found that the repeats of EPIYA motif in a protein are highly non-random. As the probability of one protein sequence having a copy of EPIYA motif is 1.13E-02 $(104,116 / 9,216,047)$, the expected probabilities of one protein sequence containing 24 copies of EPIYA motif are $(1.13 \mathrm{E}-02)^{2}=1.28 \mathrm{E}-04,(1.13 \mathrm{E}-02)^{3}=1.44 \mathrm{E}-06$, and $(1.13 \mathrm{E}-02)^{4}=1.63 \mathrm{E}-08$, respectively, assuming the combination of the motif in a sequence is random. The observed probabilities of one sequence containing multiple copies of EPIYA motif are much larger than the expected probabilities as shown in Table 2. Hence, the repeats of the EPIYA motif may have been resulted from evolution with biological significance. This is also reflected in Table 1, where most effectors with known EPIYA motif have 2-7 motif repeats. Thus, we suggest that multiple copies of EPIYA motif in the same protein are more likely to be functional than single motif occurrence.

\section{Distribution pattern of EPIYA motif among species}

The NR database contains proteins sequences from 27,432 genuses and 121,718 species. Among them the sequences from 2675 genuses and 4646 species contain at least one copy of EPIYA motif, and 368 genuses and 587 species have proteins containing at least two copies 
Table 1 Experimentally determined tyrosine-phosphorylated effectors and their motifs

\begin{tabular}{|c|c|c|c|c|c|c|c|c|}
\hline \multirow{2}{*}{$\frac{\text { Effector }}{\text { CagA }}$} & \multirow{2}{*}{$\begin{array}{l}\text { Pathogen } \\
\text { H.Ppylori }\end{array}$} & \multirow{2}{*}{$\begin{array}{l}\text { Locus of protein } \\
\text { NP_207343 }\end{array}$} & \multicolumn{6}{|c|}{ Motif (phosphorylated Y position) } \\
\hline & & & EPIYAKVNK & Y-899 & EPIYTQVAK & Y-918 & EPIYATIDD & Y-972 \\
\hline \multirow[t]{3}{*}{ Ankyrin } & Anaplasma phagocytophilum & ABB84853 & ESIYEEIKD & Y-940 & ESIYEEIKD & Y-967 & ESIYEEIKD & Y-994 \\
\hline & & & EDLYATVGA & $Y-1028$ & ESIYADPFD & Y-1056 & ESIYADPFA & Y-1074 \\
\hline & & & EPIYATVKK & Y-1098 & & & & \\
\hline \multirow{2}{*}{ BepD } & Bartonella henselae & YP_034066 & EPLYAQVNK & $Y-32$ & NPLYEGVGG & $Y-114$ & NPLYEGVGS & Y-176 \\
\hline & & & EPLYAQVNK & $Y-211$ & NPLYEGVGG & Y-293 & NPLYEGVGP & Y-355 \\
\hline BepE & Bartonella henselae & YP_034067 & EPLYATVNK & $Y-37$ & ETIYTTVSS & Y-91 & & \\
\hline \multirow[t]{2}{*}{ BepF } & Bartonella henselae & YP_034068 & TPLYATPSP & Y-149 & EPLYATPLP & $Y-213$ & EPLYATPLP & $Y-241$ \\
\hline & & & EPLYATAAP & Y-297 & EPLYATPLP & $Y-269$ & & \\
\hline Tir & Escherichia Eoli & AAC38390 & EHIYDEVAA & $Y-474$ & & & & \\
\hline Tir & Citrobacter rodentium & AAL06376 & EPIYDEVAP & $Y-468$ & & & & \\
\hline Trap & Chlamydie trachomatis & YP_001654788 & ENIYENIYE & $Y-136$ & ENIYENIYE & $Y-238$ & ENIYENIYE & $Y-390$ \\
\hline
\end{tabular}

CagA: cytotoxin associated gene A[7,8,10,52-56]; BepD: Bartonella henselae protein D[14-16,57]; BepE: Bartonella henselae protein E[14-16,57]; BepF: Bartonella henselae protein F[14-16,57]; Tir: translocated intimin receptor[58-60]; Trap: Translocated actin-recruiting protein[61-63]. The first five amino acids of the listed sequences in the table correspond to the EPIYA motif.

of EPIYA motif. The proteins with the EPIYA motif are mainly distributed in lower organisms. As shown in Table 3, the probability of a genus/species containing proteins with the EPIYA motif in archaea, viruses or bacteria is much higher than that in eukaryotes. This indicates that with evolution advanced species mostly lost the EPIYA motif together with its functions for host- pathogen interactions.

We listed top 10 species and genuses with most EPIYAmotif containing proteins for the groups of archaea, viruses, bacteria, protista, fungi, metazoa and viridiplantae (Additional File 1). In archaea, Methanococcus is the genus that includes the most EPIYA-motif containing proteins. In viruses, Potyvirus is the highest in number of EPIYAmotif containing proteins among genuses while Bovine Viral Diarrhea Virus is the highest among species. The top four genuses (and the corresponding species) in bacteria are Helicobacter (Helicobacter pylori), Clostridum (Clostridum botulinum, Clostridum perfringens), Bacillus (Bacillus cereus) and Anaplasma (Anaplasma phagocytophilum). Plasmodium (Plasmodium falciparum) and Tetrahymena (Tetrahymena thermophila) are the top genuses in protista. In fungi and viridiplantae, the corresponding top genuses are Candida (Candida tropicalis) and Oryza
(Oryza sativa), respectively. Two well-studied genuses Drosophila (Drosophila melanogaster) and Homo (Homo sapiens) take the top two in metazoa. It should be noted that the data in Additional File 1 are biased, with widely studied species such as Helicobacter pylori having the same gene sequenced many times, while some other species have incomplete proteomes. Nevertheless, this table in Additional File 1 provides some interesting reference for known and putative pathogens with effectors.

Bacterial pathogens can be divided to two types. Some can enter host cells, e.g., Chlamydia and Anaplasma. They are known as intracellular pathogens and most of them have T3SS or T4SS. Some other bacteria are extracellular pathogens with T3SS or T4SS, such as Helicobacter pylori and Campylobacter. As shown in Additional File 1, numerous bacteria containing multiple copies of EPIYA motif belong to pathogens, such as Anaplasma (Anaplasma phagocytophilumn, ranking 4th in the species list) and Chlamydia (Chlamydia trachomatis, ranking 10th in the species list), both of which are intracellular pathogens. Helicobacter (ranking 1st in both genus and species list) and Campylobacter (ranking 10th in the genus list) contain T4SS[18]. Some other T4SS-containing species are not listed in Additional File 1, such as Wolbachia (ranking

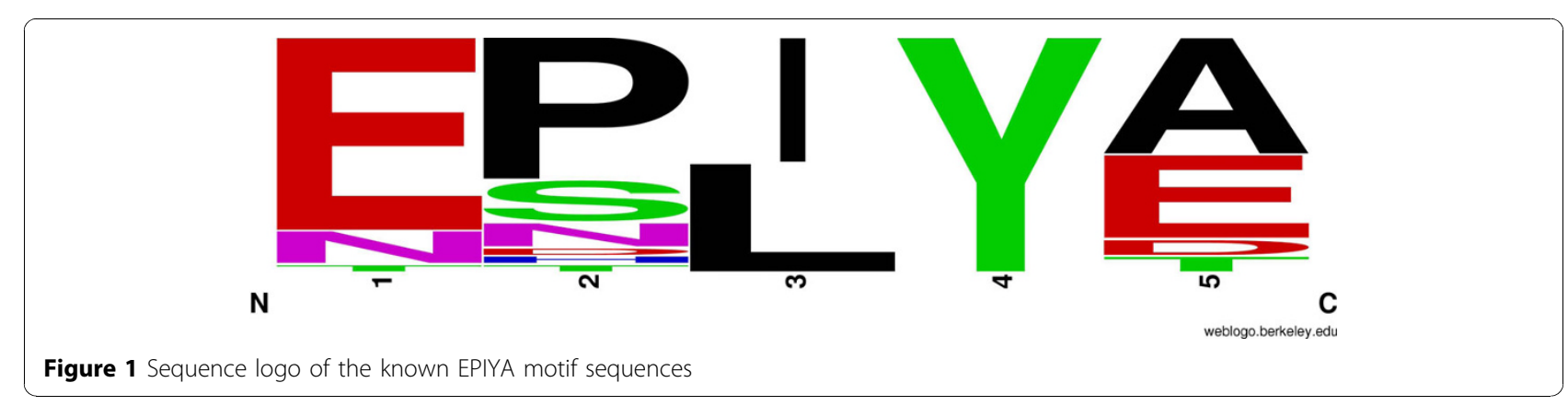


Table 2 Distribution of protein sequences containing the EPIYA motif

\begin{tabular}{cccc}
\hline Number of motif repeats in one protein & Number of protein sequences & Observed Frequency & Expected Frequency \\
\hline 29 & 1 & $1.09 \mathrm{E}-07$ & $3.44 \mathrm{E}-57$ \\
\hline 14 & 2 & $2.17 \mathrm{E}-07$ & $5.52 \mathrm{E}-28$ \\
\hline 13 & 2 & $2.17 \mathrm{E}-07$ & $4.88 \mathrm{E}-26$ \\
\hline 12 & 1 & $1.09 \mathrm{E}-07$ & $4.32 \mathrm{E}-24$ \\
\hline 10 & 1 & $1.09 \mathrm{E}-07$ & $3.39 \mathrm{E}-20$ \\
\hline 9 & 3 & $3.26 \mathrm{E}-07$ & $3.00 \mathrm{E}-18$ \\
\hline 8 & 6 & $6.51 \mathrm{E}-07$ & $2.65 \mathrm{E}-16$ \\
\hline 7 & 10 & $1.09 \mathrm{E}-06$ & $2.35 \mathrm{E}-14$ \\
\hline 6 & 32 & $3.47 \mathrm{E}-06$ & $2.08 \mathrm{E}-12$ \\
\hline 5 & 55 & $5.97 \mathrm{E}-06$ & $1.84 \mathrm{E}-10$ \\
\hline 4 & 173 & $1.88 \mathrm{E}-05$ & $1.63 \mathrm{E}-08$ \\
\hline 3 & 916 & $9.94 \mathrm{E}-05$ & $1.44 \mathrm{E}-06$ \\
\hline 2 & 1913 & $2.08 \mathrm{E}-04$ & $1.28 \mathrm{E}-04$ \\
\hline 1 & 104116 & $1.13 \mathrm{E}-02$ & $1.13 \mathrm{E}-02$ \\
\hline
\end{tabular}

Expected frequency is the expected probability if the combination of the motif in a protein sequence is random.

13th in the genus list), Escherichia (ranking 18th in the genus list), Mycobacterium (ranking 23rd in the genus list) and Bartonella (ranking 27th in the genus list). Furthermore, we also found that in protista most top 10 species are unicellular parasites that can live in host cells to survive and reproduce by subverting of signalling pathways and inhibiting apoptosis of host cells[19]. However, the pathogens mediators responsible for this modulation are still unknown[20]. Those intracellular protozoan parasites include Plasmodium (ranking 1st in the genus list), Leishmania, Trichomonas, Cryptosporidium and Giardia (correspondingly ranking 58th in the genus list). Table 4 lists most known pathogens including intracellular bacteria (Mycobacteriaceae, Legionellales, Chlamydiales, Rickettsiales and Listeriaceae), extracellular bacteria with T3SS or T4SS (Enterobacteriaceae, Campylobacterales and Rhizobiales) and intracellular protozoan parasites (Apicomplexa and Kinetoplastida), representing 1319 species in total with and without the EPIYA motif. We analyzed the distribution of EPIYA motif in the potential effectors in these pathogens in Figure 2. 310 out of 4646 species with the EPYIA motif belong to such pathogens, and the percentage $(310 / 4646=6.67 \%)$ is much higher than that of such pathogens (with and without the EPIYA motif) in all species $\quad(1319 / 121,718=1.08 \%) \quad(p$-value $<0.0001$, odds ratio=6.54). We also found that the percentage of species with the EPYIA motif belonging to pathogens increases significantly with the increase of EPIYA motif repeats in a protein sequence.

3. Distribution pattern of EPIYA-motif containing proteins In our search result, there are totally 3115 protein sequences with at least two EPIYA motif repeats. Among them, most are CagA of Helicobacter pylori as

Table 3 Distribution of EPIYA-motif containing proteins at genus and species levels (as of July $6^{\text {th }}$ 2009)

\begin{tabular}{|c|c|c|c|c|c|c|c|c|c|c|}
\hline \multirow{3}{*}{$\begin{array}{l}\text { Groups } \\
\text { Archaea }\end{array}$} & \multicolumn{5}{|c|}{ Number of genuses } & \multicolumn{5}{|c|}{ Number of species } \\
\hline & \multirow{2}{*}{\begin{tabular}{|l} 
total \\
109 \\
\end{tabular}} & \multicolumn{2}{|c|}{$\begin{array}{l}\text { With copies of motif } \geq 1 \\
(\%)\end{array}$} & \multicolumn{2}{|c|}{$\begin{array}{l}\text { With copies of motif } \geq 2 \\
(\%)\end{array}$} & \multirow{2}{*}{\begin{tabular}{|c|} 
total \\
330 \\
\end{tabular}} & \multicolumn{2}{|c|}{$\begin{array}{l}\text { With copies of motif } \geq 1 \\
(\%)\end{array}$} & \multicolumn{2}{|c|}{$\begin{array}{c}\text { With copies of motif } \geq 2 \\
\text { (\%) }\end{array}$} \\
\hline & & 49 & $44.95 \%$ & 19 & $17.43 \%$ & & 90 & $27.27 \%$ & 28 & $8.48 \%$ \\
\hline Viruses & 623 & 221 & $35.47 \%$ & 18 & $2.89 \%$ & 6443 & 433 & $6.72 \%$ & 30 & $0.47 \%$ \\
\hline Bacteria & 1198 & 560 & $46.74 \%$ & 209 & $17.45 \%$ & 6291 & 1398 & $22.22 \%$ & 360 & $5.72 \%$ \\
\hline Eukaryota & 35499 & 1828 & $5.15 \%$ & 122 & $0.34 \%$ & 108654 & 2725 & $2.51 \%$ & 169 & $0.16 \%$ \\
\hline -Protista & 1263 & 109 & $8.63 \%$ & 18 & $1.43 \%$ & 3747 & 186 & $4.96 \%$ & 32 & $0.85 \%$ \\
\hline -Fungi & 1509 & 121 & $8.02 \%$ & 40 & $2.65 \%$ & 5772 & 206 & $3.57 \%$ & 52 & $0.90 \%$ \\
\hline -Metazoa & 22309 & 662 & $2.97 \%$ & 49 & $0.22 \%$ & 62097 & 826 & $1.33 \%$ & 68 & $0.11 \%$ \\
\hline -Viridiplantae & 10418 & 936 & $8.98 \%$ & 15 & $0.14 \%$ & 37038 & 1507 & $4.07 \%$ & 17 & $0.05 \%$ \\
\hline total & 37429 & 2658 & $7.10 \%$ & 368 & $0.98 \%$ & 121718 & 4646 & $3.82 \%$ & 587 & $0.48 \%$ \\
\hline
\end{tabular}

Data in this table presents the numbers of genuses/species with proteins containing the EPIYA motif versus total number of genuses/species in NR. The Eukaryota group is divided into protista, fungi, metzoa and viridiplantae. 
Table 4 Known intracellular bacterial pathogens or bacteria containing III/IV type secretion system, and intracellular parasitic protozoan

\begin{tabular}{|c|c|c|c|c|c|}
\hline Bacteria & & & Protista & & \\
\hline Genus & Type & Number of species & Genus & Type & Number of species \\
\hline Enterobacteriaceae & & 245 & Apicomplexa & & 187 \\
\hline Salmonella & T3SS & & Babesia & IPP & \\
\hline Yersinia pestis & T3SS & & Cryptosporidium & IPP & \\
\hline Shigella & T3SS & & Plasmodium & IPP & \\
\hline Escherichia & T3SS & & Isospora & IPP & \\
\hline Campylobacterales & & 76 & Toxoplasma & IPP & \\
\hline Campylobacter & T4SS & & Theileria & IPP & \\
\hline Helicobacter & T4SS & & & & \\
\hline Wolinella & T4SS & & & & \\
\hline Rhizobiales & & 346 & Kinetoplastida & & 120 \\
\hline Brucella & $\mathrm{IPB}$ & & Leishmania & IPP & \\
\hline Bartonella & $\mathrm{IPB}$ & & Trypanosoma & IPP & \\
\hline Agrobacterium & T4SS & & & & \\
\hline Rickettsiales & & 83 & & & \\
\hline Anaplasma & $\mathrm{IPB}$ & & & & \\
\hline Ehrlichia & $\mathrm{IPB}$ & & & & \\
\hline Wolbachia & $\mathrm{IPB}$ & & & & \\
\hline Rickettsia & $\mathrm{IPB}$ & & & & \\
\hline Chlamydiae & & 23 & & & \\
\hline Chlamydia & $\mathrm{IPB}$ & & & & \\
\hline Legionellales & & 62 & & & \\
\hline Legionella & $\mathrm{IPB}$ & & & & \\
\hline Coxiella & $\mathrm{IPB}$ & & & & \\
\hline Rickettsiella & $\mathrm{IPB}$ & & & & \\
\hline Mycobacteriaceae & & 168 & & & \\
\hline Mycobacterium & $\mathrm{IPB}$ & & & & \\
\hline Listeriaceae & & 9 & & & \\
\hline Listeria & $\mathrm{IPB}$ & & & & \\
\hline
\end{tabular}

this protein has been extensively studied, and 689 out of 3115 are hypothetical proteins whose functions have not been identified. Based on protein functions, the top 40 proteins ranking by occurrence under each protein function type are widely distributed. They not only exist in achaea, viruses and bacteria, but also are found in protista, metazoa and viridiplantae. Besides the known EPIYA-motif containing effectors ankryin and Tarp, they also involve enzymes related to DNA, ATP and tRNA, transcription regulators, tumor suppressors, different types of kinases, zinc-finger proteins, ubiquitin and various metabolic enzymes (Table 5).

Although many of these predicted effectors are false positives and the EPIYA motif may not be functional in them, a significant portion of them is likely to be true effectors. As known effectors, ankyrin and TPR (tetratricopeptide repeat) are related to protein-protein interaction[21,22]. Considering the sequence similarity of the above proteins, 44 sequences of ankryin are highly similar among each other and come exclusively from Anaplasma phagocytophilum, Wolbachia endosymbiont and Ehrlichia sp., all of which belong to Rickettsiales. Except the sequences from Haliangium ochraceum (ZP_03879805 and ZP_03880192), other sequences of TPR repeat-containing proteins are also similar and they are from Trichodesmium erythraeum, Stigmatella aurantiaca, Acaryochloris marina, Cyanothece sp. and Microcoleus chthonoplastese. For the 20 hypothetical proteins, YP_034066 and YP_001610012 (Bartonella), YP_153762 and YP_002563468 (Anaplasma), XP_001623017 and XP_001636029 (Nematostella), ZP_01620341 and ZP_01622571 (Lyngbya), 


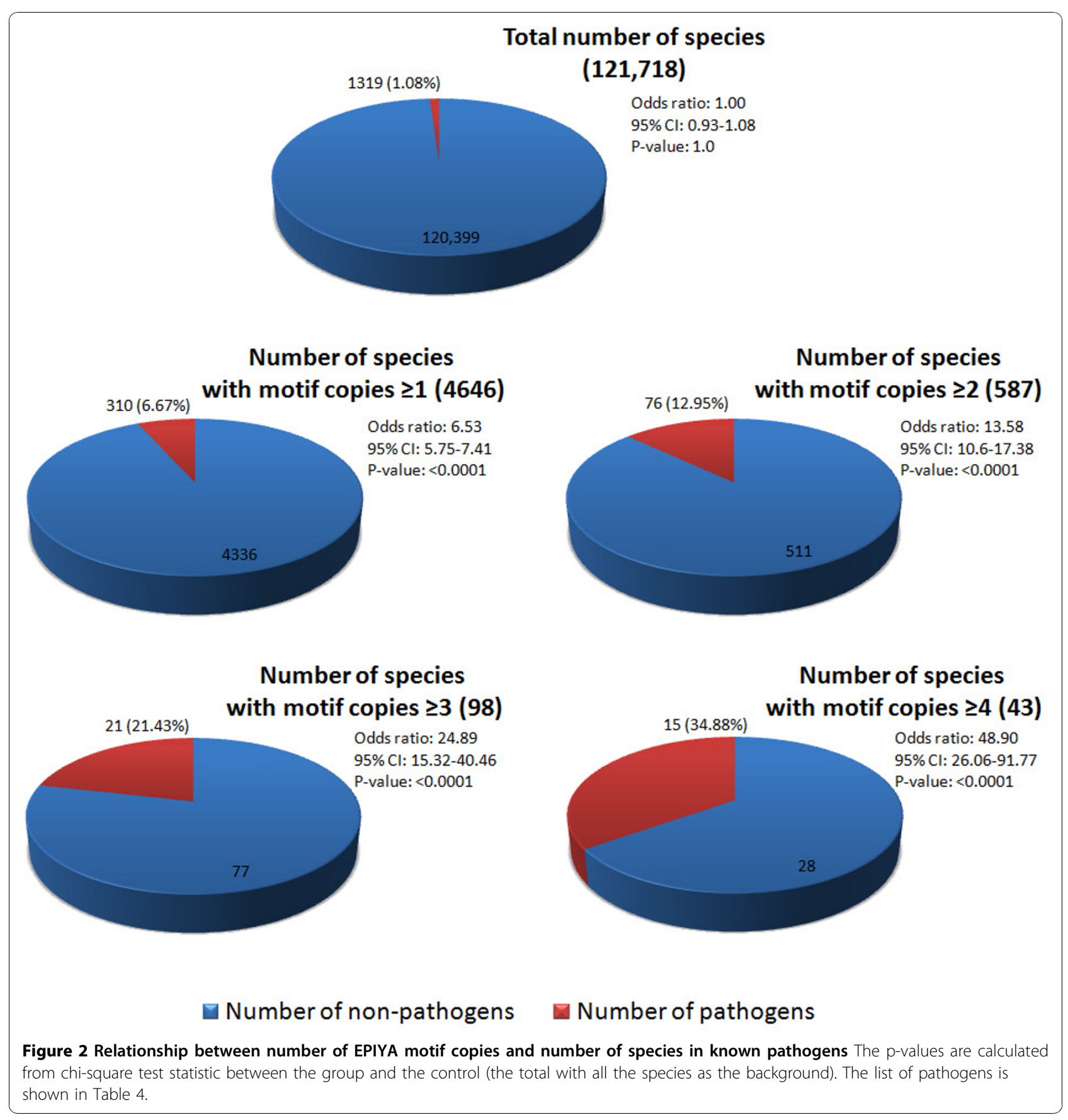

XP_001468598 and XP_001686356 (Leishmania) are similar pairs in sequences (with more than $30 \%$ sequence identity in each pair), and two proteins in a pair are from the same genus. The EPIYA motif in these proteins is highly conserved during evolution, and it may play similar roles as the motif in CagA.

Among proteins containing at least four copies of EPIYA motif (Additional File 2) with 286 sequences in total, most of them are from bacteria, especially from intracellular bacterial pathogens or extracellular bacterial pathogens with T3SS or T4SS, and some are from protist, e.g., intracellular protozoan parasites. Four out of eight known effectors (CagA, Ankyrin, BepD, and Tarp) are found in these sequences, and thus other proteins from bacteria and protista in Additional File 2 may also be effectors. An interesting observation is that the percentage of protein sequences having the EPIYA motif in archaea is the highest among all groups (see Table 3), but none of these archaeal proteins contain four or more copies of EPIYA motif. Previous studies revealed 
Table 5 Distribution of top 40 protein sequences containing at least two copies of EPIYA motif

\begin{tabular}{|c|c|c|c|c|c|c|c|c|}
\hline \multirow[t]{2}{*}{ Protein Name } & \multicolumn{8}{|c|}{ Number of proteins (number of genuses) } \\
\hline & Total & Archaea & Viruses & Bacteria & Protista & Fungi & Metazoa & Viridiplantae \\
\hline CagA & $1015(1)$ & & & $1015(1)$ & & & & \\
\hline hypothetical protein & $689(186)$ & $15(10)$ & $10(6)$ & $242(88)$ & $162(19)$ & $78(28)$ & $127(25)$ & $55(11)$ \\
\hline ATP* & $81(21)$ & $2(2)$ & & $68(11)$ & $6(4)$ & $4(3)$ & & $1(1)$ \\
\hline Ankryin & $55(7)$ & & & $51(3)$ & & & $4(4)$ & \\
\hline $\mathrm{DNA}^{*}$ & $52(34)$ & $3(3)$ & & $40(25)$ & $7(4)$ & $1(1)$ & & $1(1)$ \\
\hline Kinase & $43(28)$ & $5(2)$ & & $23(15)$ & $4(3)$ & & $11(8)$ & \\
\hline zinc finger protein & $43(11)$ & & & & & & $43(11)$ & \\
\hline TPR repeat protein & $33(15)$ & & & $33(15)$ & & & & \\
\hline Polyprotein & $24(2)$ & & $24(2)$ & & & & & \\
\hline $\operatorname{Sec} A$ & $23(14)$ & & & $23(14)$ & & & & \\
\hline Peptidase & $19(12)$ & $1(1)$ & & $16(9)$ & $1(1)$ & & $1(1)$ & \\
\hline dynein heavy chain & $17(13)$ & & & & $4(2)$ & $1(1)$ & $11(9)$ & $1(1)$ \\
\hline elongation factor 2 & $15(7)$ & & & & $10(2)$ & $1(1)$ & $4(4)$ & \\
\hline Palmdelphin & $14(9)$ & & & & & & $14(9)$ & \\
\hline tRNA* & $14(11)$ & $2(1)$ & & $10(8)$ & $1(1)$ & $1(1)$ & & \\
\hline glycogen synthase & $13(1)$ & & & $13(1)$ & & & & \\
\hline GTP-binding & $13(3)$ & & & $12(2)$ & $1(1)$ & & & \\
\hline transcriptional regulator & $13(8)$ & $1(1)$ & & $9(4)$ & & $3(3)$ & & \\
\hline unc-119 homolog & $13(6)$ & & & & & & $13(6)$ & \\
\hline FAT tumor suppressor homolog 3 & $12(9)$ & & & & & & $12(9)$ & \\
\hline nuclear ribonucleoprotein & $12(9)$ & & & & $1(1)$ & $10(7)$ & & $1(1)$ \\
\hline 4-alpha-glucanotransferase & $9(1)$ & & & $9(1)$ & & & & \\
\hline paternally expressed 3 & $8(6)$ & & & & & & $8(6)$ & \\
\hline Striatin & $8(7)$ & & & & & & $8(7)$ & \\
\hline Tarp & $8(1)$ & & & $8(1)$ & & & & \\
\hline nuclear autoantigen & $7(6)$ & & & & & & $7(6)$ & \\
\hline putative mannosyltransferase & $7(1)$ & & & $7(1)$ & & & & \\
\hline Ubiquitin & $7(6)$ & & & & $5(4)$ & $2(2)$ & & \\
\hline 265 proteasome regulatory subunit & $6(3)$ & & & & & & & $6(3)$ \\
\hline cell division protein & $6(4)$ & $3(3)$ & & $1(1)$ & & & & \\
\hline centaurin, delta 3 & $6(5)$ & & & & & & $6(5)$ & \\
\hline fat tumor suppressor homolog 2 & $6(5)$ & & & & & & $6(5)$ & \\
\hline glycosyl transferase & $6(5)$ & & & $6(5)$ & & & & \\
\hline guanine nucleotide exchange factor & $6(6)$ & & & & & & $6(6)$ & \\
\hline cytochrome c oxidase subunit VI & $5(4)$ & & & & $5(4)$ & & & \\
\hline PEG3 & $5(5)$ & & & & & & $5(5)$ & \\
\hline polyketide synthase & $5(4)$ & & & $3(3)$ & $2(1)$ & & & \\
\hline polysaccharide biosynthesis protein & $5(3)$ & & & $5(3)$ & & & & \\
\hline TatD-related deoxyribonuclease & $5(1)$ & & & $5(1)$ & & & & \\
\hline translation initiation factor & $5(4)$ & & & $2(2)$ & $2(1)$ & $1(1)$ & & \\
\hline
\end{tabular}

ATP* includes ATPase, ABC transporter, ATP-binding protein, and ATP-dependent helicase; DNA* includes DNA photolyase, DNA primase, DNA repair protein, DNA-binding protein, and DNA mismatch repair protein; kinases* includes histidine kinase, protein kinase, hexokinase, serine kinase, and fyn-related kinase; tRNA* includes tRNA synthetase, tRNA formyltransferase, and tRNA ligase. 
that CagA sequences with more EPIYA-motif occurrences are more virulent[6]. Since archaea and other organisms have relationships of either mutualism or commensalsim and till now there is no clear evidence for the existence of archea parasites[23,24], it is unlikely that the archaeal proteins containing the EPIYA motif act as pathogen effectors. Compared to other groups, archaea is not well studied, but we can still find some interesting examples, such as Methanobrevibacter smithii (ranking 5th in the species list in Additional File 1). It is the most common commensal archaea in the human gut and plays an important role in digesting polysaccharides, while it may not benefit the host directly. We speculate that EPIYA- motif containing proteins of Methanobrevibacter smithii may have some biological functions in this commensal interaction.

Many functions listed in Table 5 may reflect the fact that these proteins may have multiple functions other than phosphorylation-induced signalling control in the host cell. Some of these proteins may mimic host protein functions. For example, it was suggested that CagA functions as a prokaryotic mimic of the eukaryotic Grb2-associated binder (Gab) adaptor protein[25]. Some of the predicted effectors may mimic singling proteins, such as HPK (histidine protein kinase) listed in Table 5, which is an important part of two-component signal transduction system that recognizes and transmits environmental signals[26]. Some known effectors induce protein expressions with increased expression of RNA polymerase[27]. It is not surprising to see a significant number of proteins in Table 5 are related to protein synthesis, such as RNA polymerase, elongation factor, and helicase. It is noted that CagA itself also contains an RNA polymerase domain based on a BLAST search. These connections also suggest the ancestor proteins of the predicted effectors. Many of the proteins listed in Table 5 are ancient house-keeping genes. The predicted effectors might have evolved from these house-keeping genes by mimicking the host genes. Furthermore, over evolution some of the effectors or their ancestors might have evolved into genes with different functions unrelated to host-pathogen interactions, such as EPIYAmotif containing proteins in archaea and metazoan.

\section{HMMs based on EPIYA and SH2-binding motifs}

(1) Building HMM based on KK, R4, Tarp and Tir motifs It is known that biological effects of CagA induced by phosphorylation depend on the binding to the SH2 domain. Different combinations of the five amino acids after phosphorylated tyrosine (pY) will bind different SH2 domains and cause different downstream effects. There are two known motifs in CagA that could bind to SH2 domain - EPIYAKVNK and EPIYATIDD (F), which are referred to as KK motif and R4 motif
$[28,29]$, respectively. For the Tir protein, we retrieved all sequences in Escherichia coli and Citrobacter rodentium with the pattern of EHIYDEVAA(P) and built a motif (named as Tir motif). We did the same for Tarp protein, yielding the motif ENIYENIYE (named as Tarp motif). We extracted sequences of known KK, R4, Tir and Tarp motifs in proteins CagA, Tir and Tarp (including their variants), and then built HMMs one by one. Figure 3 shows the sequence logo of each motif. Comparing with the sequence logo in Figure 1, the 9-mer motifs are more conserved and specific. This will help reduce the false positive rate in identifying putative effectors, while the downstream $\mathrm{SH} 2$ binding partners are also predicted at the same time.

(2) Search results by using HMMs based on KK, R4, Tarp, and Tir motifs Using HMMs based on KK, R4, Tarp and Tir motifs to search the protein sequences containing the EPIYA motif as described above, we found that the results are widespread in many species. In this paper we only focus on the results in bacteria and protista. As shown in Table 6, CagA KK (EPIYAKVNK) motif exists in some known phosphorylation effectors, e.g., Beps (BepD, BepE, BepH) and Tir. CagA R4 (EPIYATIDD) motif exists in Tarp. Both KK and R4 motifs exist in ankyrin. Among 8 proteins for building our EPIYA-motif based HMM, BepF is the only one containing neither KK nor R4 motif. The Tir protein just have one motif - Tir motif in Table 1, while BAF52548 (Tir of E. coli) contains two motifs, i.e., Tir (EHIYDEVAA) motif and EPIYAKIQR, similar to the KK motif. Tarp protein (YP_001654788) of Chlamydia trachomatis contains not only the Tarp motif (ENIYENIYE), but also another motif ENIYESIDD, which is similar to the R4 motif. It reveals that although these proteins are not similar in global sequences (weak similarity exists between Beps sequences), they share the same or similar motifs with significant functional relationships.

\section{Prediction of new effectors}

Based on the above HMMs of KK, R4, Tir and Tarp motifs, we predicted some new pathogen effectors (Additional File 3) and we assessed them based on the literature. The details of predicted effectors have been listed in Additional File 4, 5, 6, 7.

(1) Bartonella tribocorum: Since BepH contains the EPLYAQVNK (YP_001610013, Y-8) motif (KK motif), we predicted it as a phosphorylation effector like BepDF secretory proteins.

(2) Lawsonia intracellularis: Lawsonia intracellularis is an obligate intracellular bacterial pathogen, which infects a wide range of animals, mainly pigs, and causes proliferative enteropathy - a type of contagious diseases $[30,31]$. Its symptoms are acute, including diarrhea, loss 


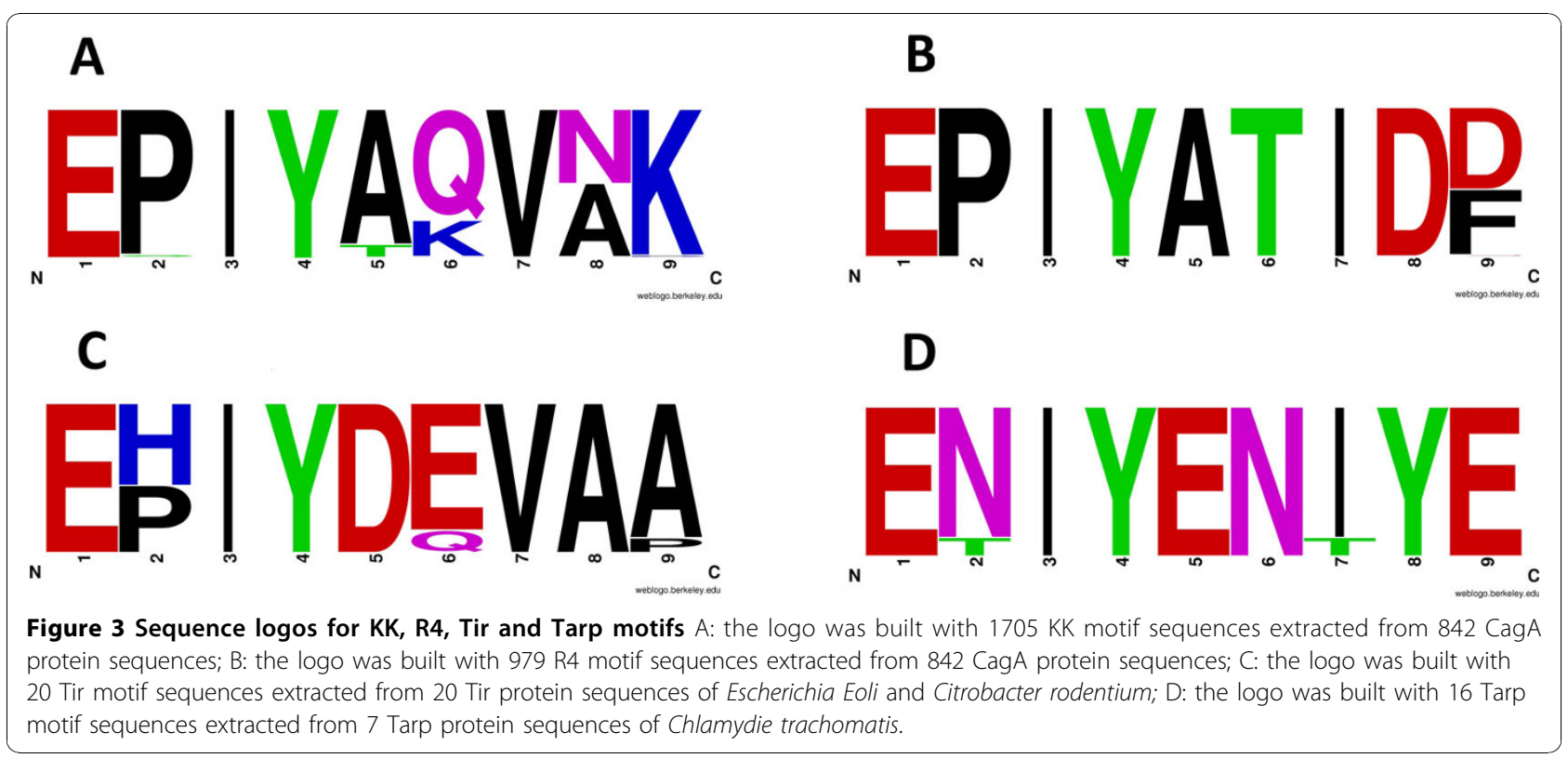

of appetite and stunting. After an initial close association with the cell membrane of the enterocytes, Lawsonia intracellularis is endocytosed into host cell[32]. Infected host cells are inhibited in maturation, continue to undergo mitosis and proliferation, and at last form hyperplastic crypts, but the mechanism is unknown[33]. The genome sequence of Lawsonia intracellularis indicates that it may possess a type III secretion system, which may assist the bacterium during cell invasion and evasion of the host's immune system and could be a mechanism for inducing cellular proliferation[34,35], but its effectors secreted by T3SS was never reported. Current database contains 20 proteins of Lawsonia intracellularis with the EPIYA motif and all of them are from strain PHE/MN1-00. The maximum sequence identity between any two of these 20 proteins is $22 \%$ and most of them are enzymes, e.g. ATP synthase. Among them, in the HMM search result by using the R4 motif, we found that hypothetical protein L10666 (YP_595041) contains two copies of EPIYA motif (EPIYAEIKT Y-149, EPIYAEIKT Y-186), which are similar to the R4 and Tir motifs, respectively. Thus, we speculate that this protein might be the effector of Lawsonia intracellularis to interact with intestinal epithelial cells.

(3) Ehrlichia sp.: It belongs to the same family Ehrilichiaceae as Anaplasma[36]. Ankyrin of Ehrlichia sp. and ankyrin of Anaplasma share $89 \%$ sequence identity. Ankyrin (T08612) of Ehrlichia sp. contains six copies of 9-mer motifs including the KK and R4 motifs, and thus it is a likely effector of Ehlichia to interact with host.

(4) Wolbachia: Wolbachia belongs to Rickettsiales. Wolbachia is a symbiotic bacterium existing in the sex organ of many insects. Though ankyrin (AAY54257) of Wolbachia and ankryin of Anaplasma share only 15\%

Table 6 Sequences containing KK and R4 motifs in known effectors

\begin{tabular}{lllll}
\hline KK Motif & Species & Protein & pY prosition & Locus \\
\hline EPIYAKVNK & H.pylori & cagA & Y-899 & NP_207343 \\
\hline EPIYTQVAK & H.pylori & cagA & Y-918 & NP_207343 \\
\hline EPIYAKIQR & E.coli & Tir & Y-477 & BAF52548 \\
\hline EPIYATVKK & Anaplasma phagocytophilum & Ankyrin & Y-1094 & ABB84853 \\
\hline EPLYAQVNK & Bartonella henselae & BepD protein & Y-28 & YP_034066 \\
\hline EPLYATVNK & Bartonella henselae & BepE protein & Y-33 & YP_034067 \\
\hline EDLYATVGA & Anaplasma phagocytophilum & Ankyrin & Y-1024 & ABB84853 \\
\hline R4 Motif & Species & Protein & pY prosition & Locus \\
\hline EPIYATIDD & H.pylori & cagA & Y-972 & NP_207343 \\
\hline ENIYESIDD & Chlamydia trachomatis & Tarp & Y-189 & YP_001654788 \\
\hline ESIYEEIKD & Anaplasma phagocytophilum & Ankyrin & Y-990 & ABB84853
\end{tabular}


sequence identity, they contain almost exactly the same motifs. Hypothetical protein WD0942 (NP_966676), which is not similar to ankyrin in sequence, has two motifs, and one of them is EPIYATVPK(Y-318) similar the KK motif. EsorChan1 (AAP34173) contains the motif EPIYDEVYD (Y-77) similar to the Tir motif. Therefore, the above three proteins, especially the first two, are potential effectors of Wolbachia[37].

(5) Pasterurella multocida: As the major pathogen to cause swine infectious atrophic rhinitis, it secretes toxin filamentous hemagglutinin containing six copies of EPIYA motif. Based on the BLAST search results, we found that the filamentous hemagglutinin (AAK61595) of Pasterurella multocida, filamentous hemagglutinin of Bordetella pertussis and Bordetella Parapertussis share $\sim 30 \%$ sequence identity [3840]. Filamentous hemagglutinin, the major virulence factor of Bordetella pertussis, not only has adhesion function, but also plays a critical role in immunomodulation. Since filamentous hemagglutinin has the sequences EDIYATINK (Y-2792), which is similar to the KK motif, EHIYADIRD (Y-2550) and ENLYAEISD (Y-2651), both of which are similar to the R4 motif, and EHLYAEINE (Y-2387), which is similar to the Tir motif, we suggest that filamentous hemagglutinin being the effector of Pasterurella multocida and it might be secreted by the TPS (Two-Partner Secretion) system[39]. PfhB2 (NP_244996) has four sequences that are similar to KK, R4 and Tir motifs, and thus it might be another candidate of effector in Pasterurella multocida.

(6) Haemophilus ducreyi: Haemophilus ducreyi is a facultative anaerobic Gram- negative coccobacillus and could cause the sexually transmitted disease chancroid. Large supernatant protein2 (NP_873623) of Haemophilus ducreyi has six copies of EPIYA motif. Its sequence and filamentous hemagglutinin of Bordetella pertussis share $41 \%$ sequence identity. Its sequences EPVYADLHF and EPVYADLRF are similar to the R4 motif. Hence, we suggest large supernatant protein2 (NP_873623) is a potential effector of Haemophilus ducreyi and it could be secreted by T4SS[41]. The effector can lead to immunosuppression, inhibition of proliferation, and permanent changes in host cells[42-44].

(7) Haemophilus somnus: Haemophilus somnus can survive in host cells and is the cause of a variety of systemic diseases in cattle, including thrombotic-meningoencephalitis, pneumonia, arthritis, myocarditis, septicemia and other reproductive diseases[45,46]. Cysteine protease domain YopT-type (YP_001784809) and filamentous hemagglutinin of Bordetella pertussis share $42 \%$ sequence identity. The sequence EPIYATLDK (Y-2933) in YP_001784809 is similar to the KK motif, EHIYEQIGE (Y-2358) similar to the Tarp motif, and EPVYDKVSA (Y-2287) similar to the Tir motif. Thus,
YP_001784809 might be the effector of Haemophilus somnus to cause immunosuppression[47].

(8) Chlamydophila pneumonia: Hypothetical protein CPj0472 (NP_300527) contains three copies of EPIYA motif. EPIYANTPE (Y-647) is similar to the KK motif, EPIYEEIGG (Y-346) is similar to the Tir motif and EPIYDEIPW (Y-681) is similar to the R4 motif. Although we did not find any similar protein through BLAST search, hypothetical protein CPj0472 (NP_300527) is a good candidate for the effector of Chlamydophila pneumonia.

(9) Leishmania major: Leishmania major could parasitize into phagocyte of human or other mammals and is responsible for the disease leishmaniasis, which is a serious zoonosis. Leishmania major have 6 proteins containing at least two copies of EPIYA motif and 4 of them are proteins with unknown functions. Among these 6 proteins, Cytochrome C oxidase subunit VI (XP_001683136) contains two copies of EPIYA motif. One is at position Y-107 with sequence EPLYQPVKK, which is similar to the KK motif. Another one is at position Y-130 with sequence EPLYDVDAA, which is similar to the Tir motif. Hence, XP_001683136 might be an effector. Hypothetical protein (XP_001686159) has three copies of EPIYA motif and the sequences are all EPLYAVTIE, which is similar to KK and R4 motifs. Hypothetical protein (XP_001686160) also has three copies of EPIYA motif and the sequences are all EPLYAVTID, which is similar to the R4 motif. In addition, hypothetical protein XP_001686159 and XP_001686160 share $43 \%$ sequence identity. Hypothetical protein (XP_001686356) has 29 copies EPIYA motif (the one with most EPIYA motifs in our data) and all sequences are the same as EPLYAVTLE, which is similar to the R4 motif. Microtubule-associated protein (XP_001687515) contains two copies of EPIYA motif. One is at Y-1543 and another is at Y-1589. The sequences for both of them are ESIYAKDYK, which is similar to the KK motif. Thus, we predict hypothetical protein (XP_001686159), hypothetical protein (XP_001686160), hypothetical protein (XP_001686356) and Microtubule-associated protein (XP_001687515) might also be the effectors of Leishmania major. For another potential effector hypothetical protein (XP_001683914), although it contains two copies of EPIYA motif (ESLYE is at Y-1006 and EHLYD is at Y-1047), they are not similar to KK, R4, Tarp or Tir motif and hence less likely to be an effector than the above five proteins.

(10) Plasmodium falciparum: Plasmodium falciparum can invade human liver cells and RBC to cause dangerous infection malaria. It contains many proteins with the EPIYA motif and 47 proteins with at least two copies of EPYIA motif. Among them, Plasmodium exported protein (XP_001347309) has three copies of motif which are all similar to the Tarp motif. The sequences and the corresponding pY sites are ESIYKNKLK (Y-331), ESIYKNKLK 
(Y-359), and ESIYKNKLE (Y-387). Thus we predict it as the effector of Plasmodium falciparum. Conserved Plasmodium protein (XP_001347469) has eight copies of EPIYA motif, RNA pseudouridylate synthase (XP_001350676) has nine copies of EPIYA motifs and hypothetical protein (XP_001351018) has three copies of EPIYA motif, but none of them contains any of KK, R4, Tir and Tarp motifs, and therefore is less likely to be the effector than Plasmodium exported protein (XP_001347309).

\section{Protein subcellular localization prediction}

We applied the subcellular localization prediction for all the predicted bacterial effectors above by using CELLO v.2.5[48](http://cello.life.nctu.edu.tw). All the associated bacteria are "gram negative". As a real effector should be secreted from a gram-negative bacterium and then enter a eukaryote host, we perform subcellular localization by using both gram-negative bacterium and eukaryote, respectively. When using gram-negative bacteria as hosting species, 9 out 11 effectors were predicted as extracellular or outer-membrane (Additional File 8). When reapplying the prediction by choosing eukaryotes as the organisms, all 11 effectors are predicted to have nuclear localization (Additional File 8). The above results show that most of our predicted effectors have expected localization attributes as effectors, which provides some supporting evidence for our effector predictions.

\section{Conclusions}

In this paper, we showed that the EPIYA motif might be a ubiquitous functional site for effectors that play an important role in pathogenicity for mediating hostpathogen interactions. Most known effectors have more than one copy of EPIYA motif. The predicted effector sequences of pathogens from the same genus are likely homologous, and those from different genuses are rarely homologous although they often share common motifs. Most pathogens are intracellular bacteria or long-term chronic infection of extracellular bacteria, e.g., H. pylori. Usually effectors are secreted by T3SS or T4SS to enter host cells, and then interfere signal transduction pathway of the host cell to disturb host cell functions, which mainly involve actin polymerization, cell proliferation, apoptosis and immunosuppression, so as to improve the abilities of survival and propagation of microorganism with host-pathogen interaction.

Our study predicted many putative effectors. We grouped the phosphorylated EPIYA motifs into four types, KK, R4, Tir and Tarp based on the sequence features of the five amino acids after $\mathrm{Y}$, and then we used them individually to build the HMM. After using the HMMs to search our database and considering the known pathogenic characteristics of pathogens, we predicted some effectors of bacteria and also suggested that using our method will discover more effectors with the EPIYA motif. Besides the discovery in bacteria, we also found that there were many protein sequences containing the EPIYA motif in protist pathogens. Intracellular protozoan parasites can live in host cells to survive and reproduce by subverting of host cell signalling[19], to induce downstream effects, e.g., inhibiting apoptosis of host cells, restructuring of the host cell cytoskeleton, and so on. However, the pathogen mediators responsible for this modulation are still unknown[20]. Based on this study, we hypothesize that during the interaction process between protist and host, there is a secretion system that can secrete effectors to disturb the signal transduction pathway of infected host and to control the apoptosis of host cells.

Our predictions provide useful hypotheses for further studies on exploring pathogenic mechanisms in the host-pathogen interactions. It also has the scientific and clinical implications for prevention and treatment of infectious diseases, as it may provide some guidance for vaccine/drug development. Having said that, it is noted that the EPIYA-motif containing protein does not exist in all intracellular bacteria, and therefore EPIYA-motif mediating interaction is only one type of various hostpathogen mechanisms. Furthermore, our prediction result is based on computation and definitely contains false positives, and thus it requires further experimental validations.

\section{Methods}

Figure 4 shows the overall workflow of this project. The major modules and steps are described as follows:

\section{Data Sources}

1. Protein sequence data: We used the NR (nonredundant) protein database at the National Center for Biotechnology Information (NCBI) in this study. All protein sequences in the FASTA format were downloaded from the NCBI site (ftp://ftp.ncbi.nih.gov/blast/db/ FASTA/nr.gz; as of July $6^{\text {th }} 2009 ; 9,216,047$ sequences). We excluded "other" sequences and "unclassified" sequences" in the database (as labelled in http://www.ncbi. nlm.nih.gov/Taxonomy/Browser/wwwtax.cgi?mode=Root).

2. Taxonomy data: The taxonomy data was obtained from the NCBI website (http://www.ncbi.nlm.nih.gov/ Taxonomy/txstat.cgi; as of July $6^{\text {th }} 2009$ ).

\section{Hidden Markov model}

A hidden Markov model was built by using Hmmer 2.3.2[49] (http://hmmer.janelia.org). We used selected sequences to run the command hmmbuild.exe for building and calibrating the HMM. We then used the HMM 


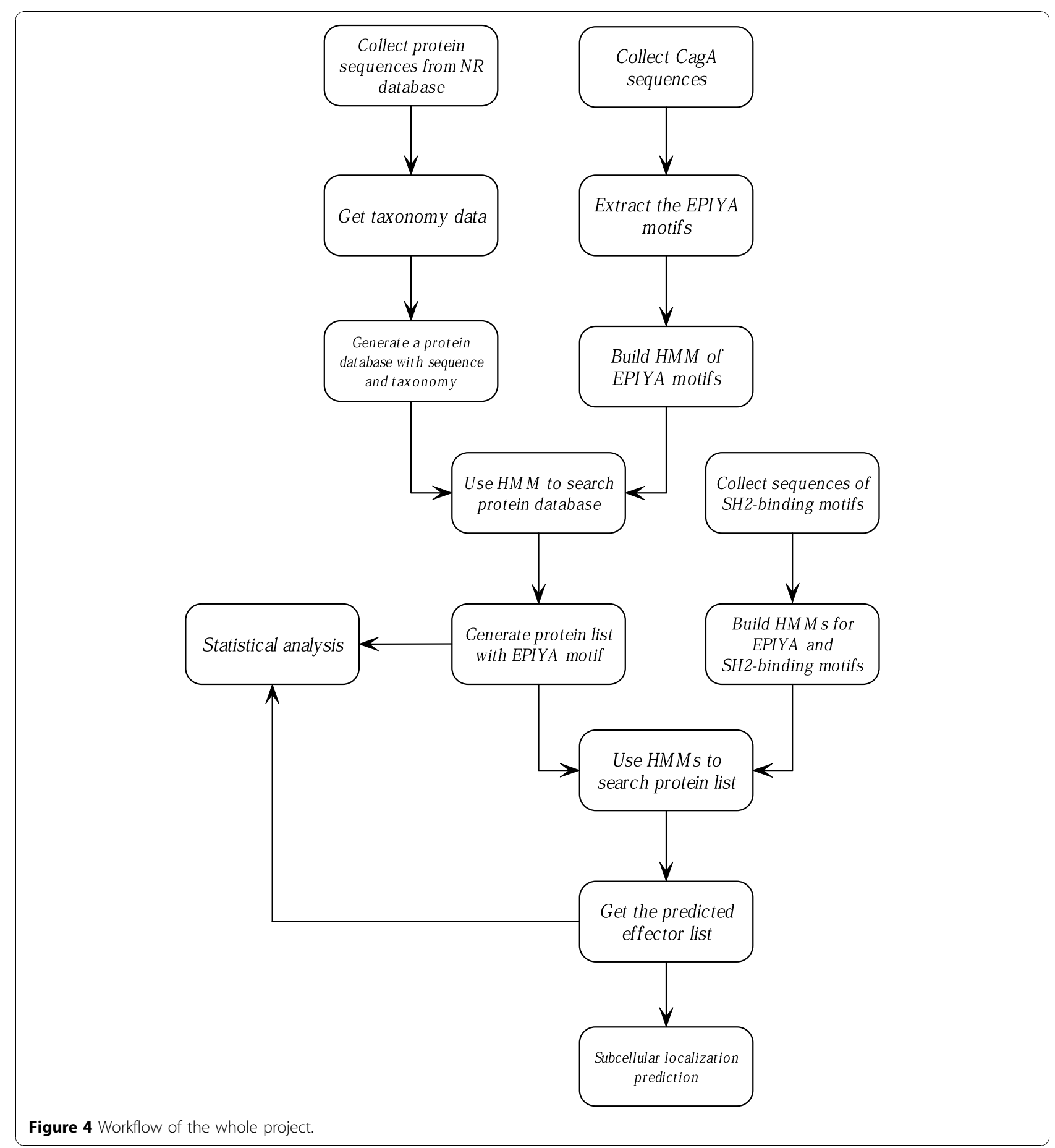

to run the command hmmsearch.exe for searching protein sequences. We used a natural cutoff of HMM score such that the last of the all known motifs is retrieved.

\section{Data analysis}

We used Perl (release ActivePerl 5.8.8) as the programming language to analyse the data and build the database. We applied SAS 9.0 (http://www.sas.com) as the statistical analysis tool and chose $\mathrm{p}<0.01$ as the significant threshold.

\section{Sequences comparison}

BioEdit 7.0 (http://www.mbio.ncsu.edu/BioEdit/bioedit. html), Lasergene 7 (http://www.dnastar.com/products/ lasergene.php), and Blast[50](http://blast.ncbi.nlm.nih. gov/Blast.cgi) were used to compare and analyse the 
protein sequences. Sequence logos were constructed using Weblogo[51].

Additional File 1: Top 10 genuses and species containing most proteins with at least two copies of EPIYA motif for each group.

Additional File 2: List of proteins that contain at least 4 EPIYA motifs. Parenthesis under Lotus: number of sequences; "**": effector confirmed by experiment; "Repeats": occurrence of EPIYA motif in a protein sequence.

Additional File 3: EPIYA motif, together with the corresponding functions of those effectors. *: predicted effectors; **: predicted motifs.

Additional File 4: This file contains a list of sequences that are similar to the KK motif in bacteria and protista.

Additional File 5: This file contains a list of sequences that are similar to the R4 motif in bacteria and protista.

Additional File 6: This file contains a list of sequences that are similar to the Tarp motif in bacteria and protista.

Additional File 7: This file contains a list of sequences that are similar to the Tir motif in bacteria and protista.

Additional File 8: This file contains top three subcellular localization prediction results of each predicted effector using gram-negative bacterium or eukaryote as the hosting organism, respectively. The values indicate the confidence of the predictions and "*" represents most likely localization.

\section{Acknowledgements}

This work was partially supported by International Exchange and Cooperation Office of Nanjing Medical University, China. It was also supported in part by US National Institute of Health [grant number R21/R33 GM078601]. Publication of thissupplement was made possible with support from the International Society of Intelligent Biological Medicine (ISIBM). This article has been published as part of BMC Genomics Volume 11 Supplement 3, 2010: The full contents of the supplement are available online at http://www.biomedcentral.com/1471-2164/11?issue=S3.

\section{Author details}

${ }^{1}$ Department of Gastroenterology, the First Affiliated Hospital of Nanjing Medical University, Jiangsu 210029, China. ${ }^{2}$ Department of Computer Science, University of Missouri, Columbia, MO 65211, USA. ${ }^{3}$ C.S. Bond Life Sciences Center, University of Missouri, Columbia, MO 65211, USA. ${ }^{4}$ Department of General Surgery, the First Affiliated Hospital of Nanjing Medical University, Jiangsu 210029, China.

\section{Authors' contributions}

SX conceived the study, carried out the programming, built EPIYA-motif HMM, performed data analysis and drafted the manuscript. CZ built EPIYAmotif HMM, performed data analysis and drafted the manuscript. YM conceived the study. JG participated in data analysis. DX conceived the study, analyzed the results, and supervised the project. All authors revised and approved the final manuscript.

\section{Competing interests}

The authors declare that they have no competing interests.

Published: 1 December 2010

\section{References}

1. Stavrinides J, McCann HC, Guttman DS: Host-pathogen interplay and the evolution of bacterial effectors. Cell Microbiol 2008, 10(2):285-292.

2. Cambronne ED, Roy CR: Recognition and delivery of effector proteins into eukaryotic cells by bacterial secretion systems. Traffic 2006, 7(8):929-939.

3. Cossart $P$, Boquet $P$, Normark $S$, Rappuoli R: Cellular microbiology emerging. Science 1996, 271(5247):315-316.
4. Niebuhr K, Dramsi S: EMBO-EBNIC workshop on cellular microbiology 'Host cell-pathogen interactions in infectious disease'. Cell Microbiol 1999, 1(1):79-84.

5. Maeda S, Mentis AF: Pathogenesis of Helicobacter pylori infection. Helicobacter 2007, 12(Suppl 1):10-14.

6. Naito M, Yamazaki T, Tsutsumi R, Higashi H, Onoe K, Yamazaki S, Azuma T, Hatakeyama M: Influence of EPIYA-repeat polymorphism on the phosphorylation-dependent biological activity of Helicobacter pylori CagA. Gastroenterology 2006, 130(4):1181-1190.

7. Mimuro H, Suzuki T, Tanaka J, Asahi M, Haas R, Sasakawa C: Grb2 is a key mediator of helicobacter pylori CagA protein activities. Mol Cell 2002, 10(4):745-755.

8. Higashi H, Tsutsumi R, Muto S, Sugiyama T, Azuma T, Asaka M, Hatakeyama M: SHP-2 tyrosine phosphatase as an intracellular target of Helicobacter pylori CagA protein. Science 2002, 295(5555):683-686.

9. Hatakeyama M: SagA of CagA in Helicobacter pylori pathogenesis. Curr Opin Microbiol 2008, 11(1):30-37.

10. Tammer I, Brandt S, Hartig R, Konig W, Backert S: Activation of Abl by Helicobacter pylori: a novel kinase for CagA and crucial mediator of host cell scattering. Gastroenterology 2007, 132(4):1309-1319.

11. Saadat I, Higashi H, Obuse C, Umeda M, Murata-Kamiya N, Saito Y, Lu H, Ohnishi N, Azuma T, Suzuki A, et al: Helicobacter pylori CagA targets PAR1/MARK kinase to disrupt epithelial cell polarity. Nature 2007, 447(7142):330-333

12. Ijdo JW, Carlson AC, Kennedy EL: Anaplasma phagocytophilum AnkA is tyrosine-phosphorylated at EPIYA motifs and recruits SHP-1 during early infection. Cell Microbiol 2007.

13. Lin M, den Dulk-Ras A, Hooka's PA, Rikihisa Y: Anaplasma phagocytophilum AnkA secreted by type IV secretion system is tyrosine phosphorylated by Abl-1 to facilitate infection. Cell Microbiol 2007, 9(11):2644-2657.

14. Dehio C: Infection-associated type IV secretion systems of Bartonella and their diverse roles in host cell interaction. Cell Microbiol 2008.

15. Schulein R, Guye P, Rhomberg TA, Schmid MC, Schroder G, Vergunst AC, Carena I, Dehio C: A bipartite signal mediates the transfer of type IV secretion substrates of Bartonella henselae into human cells. Proc Natl Acad Sci U S A 2005, 102(3):856-861.

16. Schmid MC, Schulein R, Dehio M, Denecker G, Carena I, Dehio C: The VirB type IV secretion system of Bartonella henselae mediates invasion, proinflammatory activation and antiapoptotic protection of endothelial cells. Mol Microbiol 2004, 52(1):81-92.

17. Backert S, Meyer TF: Type IV secretion systems and their effectors in bacterial pathogenesis. Curr Opin Microbiol 2006, 9(2):207-217.

18. Bereswill S, Kist M: Recent developments in Campylobacter pathogenesis. Curr Opin Infect Dis 2003, 16(5):487-491.

19. Gregory DJ, Olivier M: Subversion of host cell signalling by the protozoan parasite Leishmania. Parasitology 2005, 130(Suppl):S27-35.

20. Carmen JC, Sinai AP: Suicide prevention: disruption of apoptotic pathways by protozoan parasites. Mol Microbiol 2007, 64(4):904-916.

21. Blatch $G L$, Lassle $M:$ The tetratricopeptide repeat: a structural motif mediating protein-protein interactions. Bioessays 1999, 21(11):932-939.

22. Li J, Mahajan A, Tsai MD: Ankyrin repeat: a unique motif mediating protein-protein interactions. Biochemistry 2006, 45(51):15168-15178.

23. Cavicchioli R, Curmi PM, Saunders N, Thomas T: Pathogenic archaea: do they exist? Bioessays 2003, 25(11):1119-1128.

24. Lepp PW, Brinig MM, Ouverney CC, Palm K, Armitage GC, Relman DA: Methanogenic Archaea and human periodontal disease. Proc Natl Acad Sci U S A 2004, 101(16):6176-6181.

25. Botham CM, Wandler AM, Guillemin K: A transgenic Drosophila model demonstrates that the Helicobacter pylori CagA protein functions as a eukaryotic Gab adaptor. PLoS Pathog 2008, 4(5):e1000064.

26. Calva E, Oropeza R: Two-component signal transduction systems, environmental signals, and virulence. Microb Ecol 2006, 51(2):166-176.

27. Jasmer DP, Goverse A, Smant G: Parasitic nematode interactions with mammals and plants. Annu Rev Phytopathol 2003, 41:245-270.

28. Argent RH, Kidd M, Owen RJ, Thomas RJ, Limb MC, Atherton JC: Determinants and consequences of different levels of CagA phosphorylation for clinical isolates of Helicobacter pylori. Gastroenterology 2004, 127(2):514-523. 
29. Xu SF, Zhang GX, Shi RH, Hao B, Miao Y: polymorphism of variable region of CagA protein. Chin J Gastroenterol 2007, 12(06):357-361.

30. Drolet $R$, Larochelle $D$, Gebhart CJ: Proliferative enteritis associated with Lawsonia intracellularis (ileal symbiont intracellularis) in white-tailed deer. J Vet Diagn Invest 1996, 8(2):250-253.

31. Horiuchi $N$, Watarai M, Kobayashi $Y$, Omata $Y$, Furuoka H: Proliferative enteropathy involving Lawsonia intracellularis infection in rabbits (Oryctlagus cuniculus). J Vet Med Sci 2008, 70(4):389-392.

32. McOrist S, Jasni S, Mackie RA, Berschneider HM, Rowland AC, Lawson GH: Entry of the bacterium ileal symbiont intracellularis into cultured enterocytes and its subsequent release. Res Vet Sci 1995, 59(3):255-260.

33. Smith DG, Lawson GH: Lawsonia intracellularis: getting inside the pathogenesis of proliferative enteropathy. Vet Microbiol 2001, 82(4):331-345.

34. Kroll JJ, Roof MB, Hoffman LJ, Dickson JS, Harris DL: Proliferative enteropathy: a global enteric disease of pigs caused by Lawsonia intracellularis. Anim Health Res Rev 2005, 6(2):173-197.

35. Alberdi MP, Watson E, McAllister GE, Harris JD, Paxton EA, Thomson JR, Smith DG: Expression by Lawsonia intracellularis of type III secretion system components during infection. Vet Microbiol 2009, 139(3-4):298-303.

36. Lin M, Rikihisa Y: Obligatory intracellular parasitism by Ehrlichia chaffeensis and Anaplasma phagocytophilum involves caveolae and glycosylphosphatidylinositol-anchored proteins. Cell Microbiol 2003, 5(11):809-820.

37. Iturbe-Ormaetxe I, Burke GR, Riegler M, O'Neill SL: Distribution, expression, and motif variability of ankyrin domain genes in Wolbachia pipientis. $J$ Bacteriol 2005, 187(15):5136-5145.

38. May BJ, Zhang Q, Li LL, Paustian ML, Whittam TS, Kapur V: Complete genomic sequence of Pasteurella multocida, Pm70. Proc Natl Acad Sci U S A 2001, 98(6):3460-3465.

39. Clantin B, Hodak H, Willery E, Locht $C$, Jacob-Dubuisson F, Villeret V: The crystal structure of filamentous hemagglutinin secretion domain and its implications for the two-partner secretion pathway. Proc Natl Acad Sci U S A 2004, 101(16):6194-6199.

40. Inatsuka CS, Julio SM, Cotter PA: Bordetella filamentous hemagglutinin plays a critical role in immunomodulation, suggesting a mechanism for host specificity. Proc Natl Acad Sci U S A 2005, 102(51):18578-18583.

41. Juhas M, Crook DW, Dimopoulou ID, Lunter G, Harding RM, Ferguson DJ, Hood DW: Novel type IV secretion system involved in propagation of genomic islands. J Bacteriol 2007, 189(3):761-771.

42. Ahmed HJ, Johansson C, Svensson LA, Ahlman K, Verdrengh M, Lagergard T: In vitro and in vivo interactions of Haemophilus ducreyi with host phagocytes. Infect Immun 2002, 70(2):899-908

43. Cortes-Bratti X, Chaves-Olarte E, Lagergard T, Thelestam M: The cytolethal distending toxin from the chancroid bacterium Haemophilus ducreyi induces cell-cycle arrest in the G2 phase. The Journal of clinical investigation 1999, 103(1):107-115.

44. Svensson LA, Henning P, Lagergard T: The cytolethal distending toxin of Haemophilus ducreyi inhibits endothelial cell proliferation. Infect Immun 2002, 70(5):2665-2669.

45. Gomis SM, Godson DL, Wobeser GA, Potter AA: Intracellular survival of Haemophilus somnus in bovine blood monocytes and alveolar macrophages. Microb Pathog 1998, 25(5):227-235.

46. Lederer JA, Brown JF, Czuprynski CJ: "Haemophilus somnus," a facultative intracellular pathogen of bovine mononuclear phagocytes. Infect Immun 1987, 55(2):381-387.

47. Howard MD, Boone JH, Buechner-Maxwell V, Schurig GG, Inzana TJ: Inhibition of bovine macrophage and polymorphonuclear leukocyte superoxide anion production by Haemophilus somnus. Microb Pathog 2004, 37(5):263-271.

48. Yu CS, Chen YC, Lu CH, Hwang JK: Prediction of protein subcellular localization. Proteins 2006, 64(3):643-651.

49. Eddy SR: Profile hidden Markov models. Bioinformatics 1998, 14(9):755-763.

50. Altschul SF, Gish W, Miller W, Myers EW, Lipman DJ: Basic local alignment search tool. J Mol Biol 1990, 215(3):403-410.

51. Crooks GE, Hon G, Chandonia JM, Brenner SE: WebLogo: a sequence logo generator. Genome Res 2004, 14(6):1188-1190.

52. Poppe M, Feller SM, Romer G, Wessler S: Phosphorylation of Helicobacter pylori CagA by c-Abl leads to cell motility. Oncogene 2006.
53. Stein M, Bagnoli F, Halenbeck R, Rappuoli R, Fantl WJ, Covacci A: C-Src/Lyn kinases activate Helicobacter pylori CagA through tyrosine phosphorylation of the EPIYA motifs. Mol Microbiol 2002, 43(4):971-980.

54. Selbach M, Moese $S$, Hauck CR, Meyer TF, Backert S: Src is the kinase of the Helicobacter pylori CagA protein in vitro and in vivo. J Biol Chem 2002, 277(9):6775-6778.

55. Higashi H, Tsutsumi R, Fujita A, Yamazaki S, Asaka M, Azuma T, Hatakeyama M: Biological activity of the Helicobacter pylori virulence factor CagA is determined by variation in the tyrosine phosphorylation sites. Proc Natl Acad Sci U S A 2002, 99(22):14428-14433.

56. Tsutsumi R, Higashi H, Higuchi M, Okada M, Hatakeyama M: Attenuation of Helicobacter pylori CagA x SHP-2 signaling by interaction between CagA and C-terminal Src kinase. J Biol Chem 2003, 278(6):3664-3670.

57. Schulein R, Dehio C: The VirB/VirD4 type IV secretion system of Bartonella is essential for establishing intraerythrocytic infection. $\mathrm{Mol}$ Microbiol 2002, 46(4):1053-1067.

58. Phillips N, Hayward RD, Koronakis V: Phosphorylation of the enteropathogenic $\mathrm{E}$. coli receptor by the Src-family kinase c-Fyn triggers actin pedestal formation. Nat Cell Biol 2004, 6(7):618-625.

59. Blasutig IM, New LA, Thanabalasuriar A, Dayarathna TK, Goudreault M, Quaggin SE, Li SS, Gruenheid S, Jones N, Pawson T: Phosphorylated YDXV motifs and $\mathrm{Nck} \mathrm{SH2/SH3}$ adaptors act cooperatively to induce actin reorganization. Mol Cell Biol 2008, 28(6):2035-2046.

60. Gruenheid S, DeVinney R, Bladt F, Goosney D, Gelkop S, Gish GD, Pawson T, Finlay BB: Enteropathogenic E. coli Tir binds Nck to initiate actin pedestal formation in host cells. Nat Cell Biol 2001, 3(9):856-859.

61. Jewett TJ, Dooley CA, Mead DJ, Hackstadt T: Chlamydia trachomatis tarp is phosphorylated by src family tyrosine kinases. Biochem Biophys Res Commun 2008, 371(2):339-344.

62. Swanson KA, Crane DD, Caldwell HD: Chlamydia trachomatis speciesspecific induction of ezrin tyrosine phosphorylation functions in pathogen entry. Infect Immun 2007, 75(12):5669-5677.

63. Clifton DR, Fields KA, Grieshaber SS, Dooley CA, Fischer ER, Mead DJ, Carabeo RA, Hackstadt T: A chlamydial type III translocated protein is tyrosine-phosphorylated at the site of entry and associated with recruitment of actin. Proc Natl Acad Sci U S A 2004, 101(27):10166-10171.

64. Deng W, Vallance BA, Li Y, Puente JL, Finlay BB: Citrobacter rodentium translocated intimin receptor (Tir) is an essential virulence factor needed for actin condensation, intestinal colonization and colonic hyperplasia in mice. Mol Microbiol 2003, 48(1):95-115.

65. Yamada R, Floate KD, Riegler M, O'Neill SL: Male development time influences the strength of Wolbachia-induced cytoplasmic incompatibility expression in Drosophila melanogaster. Genetics 2007, 177(2):801-808.

66. Iturbe-Ormaetxe I, O'Neill SL: Wolbachia-host interactions: connecting phenotype to genotype. Curr Opin Microbiol 2007, 10(3):221-224.

67. McGraw EA, O'Neill SL: Wolbachia pipientis: intracellular infection and pathogenesis in Drosophila. Curr Opin Microbiol 2004, 7(1):67-70.

68. Veneti Z, Clark ME, Zabalou S, Karr TL, Savakis C, Bourtzis K: Cytoplasmic incompatibility and sperm cyst infection in different DrosophilaWolbachia associations. Genetics 2003, 164(2):545-552.

69. Mateos M, Castrezana SJ, Nankivell BJ, Estes AM, Markow TA, Moran NA: Heritable endosymbionts of Drosophila. Genetics 2006, 174(1):363-376.

70. McOrist S, Roberts L, Jasni S, Rowland AC, Lawson GH, Gebhart CJ, Bosworth B: Developed and resolving lesions in porcine proliferative enteropathy: possible pathogenetic mechanisms. J Comp Pathol 1996, 115(1):35-45

71. Lawson GH, Mackie RA, Smith DG, McOrist S: Infection of cultured rat enterocytes by lleal symbiont intracellularis depends on host cell function and actin polymerisation. Vet Microbiol 1995, 45(4):339-350

72. van Zandbergen G, Gieffers J, Kothe H, Rupp J, Bollinger A, Aga E, Klinger M, Brade H, Dalhoff K, Maass M, et al: Chlamydia pneumoniae multiply in neutrophil granulocytes and delay their spontaneous apoptosis. J Immunol 2004, 172(3):1768-1776.

73. Naiki Y, Michelsen KS, Schroder NW, Alsabeh R, Slepenkin A, Zhang W, Chen S, Wei B, Bulut $Y$, Wong MH, et al: MyD88 is pivotal for the early inflammatory response and subsequent bacterial clearance and survival in a mouse model of Chlamydia pneumoniae pneumonia. J Biol Chem 2005, 280(32):29242-29249 
74. Orth JH, Aktories K, Kubatzky KF: Modulation of host cell gene expression through activation of STAT transcription factors by Pasteurella multocida toxin. J Biol Chem 2007, 282(5):3050-3057.

75. Harper M, Boyce JD, Adler B: Pasteurella multocida pathogenesis: 125 years after Pasteur. FEMS Microbiol Lett 2006, 265(1):1-10.

76. Lax AJ, Pullinger GD, Baldwin MR, Harmey D, Grigoriadis AE, Lakey JH: The pasteurella multocida toxin interacts with signalling pathways to perturb cell growth and differentiation. Int J Med Microbiol 2004, 293(7-8):505-512.

\section{doi:10.1186/1471-2164-11-S3-S1}

Cite this article as: $\mathrm{Xu}$ et al.: Effector prediction in host-pathogen

interaction based on a Markov model of a ubiquitous EPIYA motif. BMC

Genomics 2010 11(Suppl 3):S1.

Submit your next manuscript to BioMed Central and take full advantage of:

- Convenient online submission

- Thorough peer review

- No space constraints or color figure charges

- Immediate publication on acceptance

- Inclusion in PubMed, CAS, Scopus and Google Scholar

- Research which is freely available for redistribution

Submit your manuscript at www.biomedcentral.com/submit
C Biomed Central 